УДК $550.4+552.52(234.853)$

\title{
О ПРИМЕНЕНИИ ГЕОДИНАМИЧЕСКИХ ЛИТОХИМИЧЕСКИХ ДИАГРАММ ПРИ ИЗУЧЕНИИ ТЕФРОГЕННЫХ ПЕСЧАНИКОВ
}

\author{
Фазлиахметов Александр Маратович, \\ famrb@mail.ru \\ Институт геологии - обособленное структурное подразделение \\ Уфимского федерального исследовательского центра Российской академии наук, \\ Россия, 450077, г. Уфа, ул. Карла Маркса, 16/2.
}

Актуальность. Диаграммы, позволяющие на основе литохимических особенностей кластолитов предполагать геодинамическую позицию седиментационных бассейнов, используются уже на протяжении многих десятилетий. Вместе с тем возможность их применения для изучения тефрогенных песчаников остается неясной, а результаты противоречивыми.

Цель исследования состоит в сравнительном анализе положения на наиболее часто применяемых диаграммах точек, отвечающих составу двух групп пород - тефрогенным песчаникам и вулканитам их источника сноса.

объектами исследования являются тефрогенные граувакки улутауской свиты и вулканиты (от риолитов до базальтов) урлядинской толщи Магнитогорской мегазоны Южного Урала. Улутауская свита относится к живетскому и нижней части франского яруса. Слагающие ее граувакки являются тефрогенными турбидитами и дебритами, сформированными в глубоководной впадине, расположенной у подножия энсиматической Магнитогорской островной дуги. В современном эрозионном срезе осевой зоне островной дуги соответствуют вулканиты урлядинской толщи.

Методы. В основу сопоставления положены результаты силикатного анализа граувакк улутауской свиты (202 образца) и вулканитов урлядинской толщи (202 образца). Сравнение проведено на основе диаграмм Мейнарда, Бхатии, Розера-Корша и Верма-Армстронга-Алтрина.

Результаты. Анализ диаграмм показал, что более реалистичные результаты дает применение основных вулканокластических граувакк $\left(\mathrm{SiO}_{2}<63 \%\right)$. Исключением в данном случае является диаграмма (Fe, $\left.\mathrm{O}_{3}+\mathrm{MgO}\right)$ - ТіО пределами каких-либо полей. Точки, отвечающие составу кислых разностей граувакк (SiO $>$ >63 \%), попадают на многих диаграммах в поля энсиалических островных дуг, окраин андского типа и пассивных континентальных окраин. Наилучшие результаты для кислых разностей были получены при использовании диаграммы DF1-DF2 и модифицированной диаграммы М. Бхатии $\mathrm{Al}_{2} \mathrm{O}_{3} /\left(\mathrm{CaO}+\mathrm{Na}_{2} \mathrm{O}\right)-\mathrm{K}_{2} \mathrm{O} / \mathrm{Na}_{2} \mathrm{O}$. Поля граувакк на большинстве построенных диаграмм совпадают с полями вулканитов и являются по сравнению с ними более компактными, что вызвано смешанным составом песчаников и низкой эксплозивностью базальтовых расплавов. Полученные результаты во многом не согласуются с результатами аналогичных исследований. Следовательно, выводы, получаемые при построении литохимических геодинамических диаграмм, не могут считаться окончательными и должны дополняться другими методами.

\section{Ключевые слова:}

Геодинамические диаграммы, песчаники, граувакки, энсиматическая островная дуга, девон, Магнитогорская мегазона, Южный Урал.

\section{Введение}

В практике литологических исследований наряду с современными методами реконструкций, основанными на содержании и соотношении в породах малых элементов, изотопов, акцессорных минералов и т. д., по-прежнему остаются востребованными результаты обработки литохимических данных [1-6].

За несколько предшествующих десятилетий предложено множество методов интерпретации литохимического состава обломочных пород. Суть их часто сводится к сопоставлению исследуемых образцов с эталонами. Одним из наиболее распространенных вариантов такого подхода являются диаграммы с полями, отвечающими тем или иным составам пород, обстановкам седиментации и т. д. Подобные диаграммы часто применяются при изучении «типичных» обломочных пород - кварцевых, аркозовых, литокластических песчаников, тогда как вулканокластические или тефрогенные песчаники рассматриваются гораздо реже. Поэтому интерпретацию их литохимического состава посредством диаграмм с эталонными полями нельзя считать многократно опробованным и надежным методом.
Тефрогенные песчаники во многом отличаются от песчаников других генетических типов. Прежде всего, это касается мобилизации слагающего их материала - преимущественно в результате эксплозий. Соответственно состав их зависит не только от факторов, в существенной мере определяющих состав экзолитических обломочных образований (площадь водосбора, петрофонд, климат, гидродинамические условия и др.), а теснейшим образом связан еще и с составом извергаемой лавы, степенью ее кристаллизации (наличие вкрапленников), положением вулкана относительно уровня моря, расчлененным рельефом и др. Исходя из этого ясно, что положение фигуративных точек состава тефрогенных песчаников на геодинамических диаграммах зависит от гораздо большего количества факторов, нежели положение точек более распространенных экзолитических песчаников.

В связи с изложенным представляется важным сравнить положение на распространенных геодинамических литохимических диаграммах: а) эталонных полей, нанесенных на диаграммы их авторами; б) точек, отвечающих составу тефрогенных песчаников и в) точек, отвечающих составу вулка- 
нитов питающих провинций тефрогенных песчаников. Результаты этих сопоставлений на примере хорошо изученных девонских островодужных песчаников улутауской свиты и вулканитов урлядинской толщи Магнитогорской мегазоны Южного Урала изложены в данном сообщении.

\section{Объекты изучения}

Улутауская свита сложена кластолитами всевозможных гранулометрических классов, среди которых существенно преобладают собственно граувакки, полевошпатовые и кварцево-полевошпатовые граувакки. Подчиненное значение имеют кремни.

Стратиграфическое положение улутауской свиты, согласно [7], - живетский и нижняя часть франского яруса, конодонтовые зоны hemiansatus-transitans. Мощность 700-2000 м.

Граувакки улутауской свиты сложены зернами вулканогенных пород основного, среднего и кислого состава, плагиоклазом и кварцем. Сочетания их различны [8-10]. Мобилизация обломочного материала осуществлялась в осевой зоне (в области вулканизма) Магнитогорской островной дуги в результате эксплозий, размыва нелитифицированной пирокластики и литифицированных вулканогенных образований $[9,11]$. В дальнейшем обломочный материал переносился в глубоководную впадину. С востока (в современных координатах) она была ограничена активной Магнитогорской, а с запада - потухшей Ирендыкской островными дугами (рис. 1). Основными агентами транспортировки служили турбидные и обломочные потоки.

Скорость седиментации была высокой (лавинной), чему способствовал большой объем изверженной пирокластики, крутизна островодужных склонов, сейсмичность территории и прочие факторы [12]. Соответственно интенсивного химического выветривания кластического материала не происходило, а существенных отличий состава песчаников улутауской свиты от состава вулканитов урлядинской толщи нет.
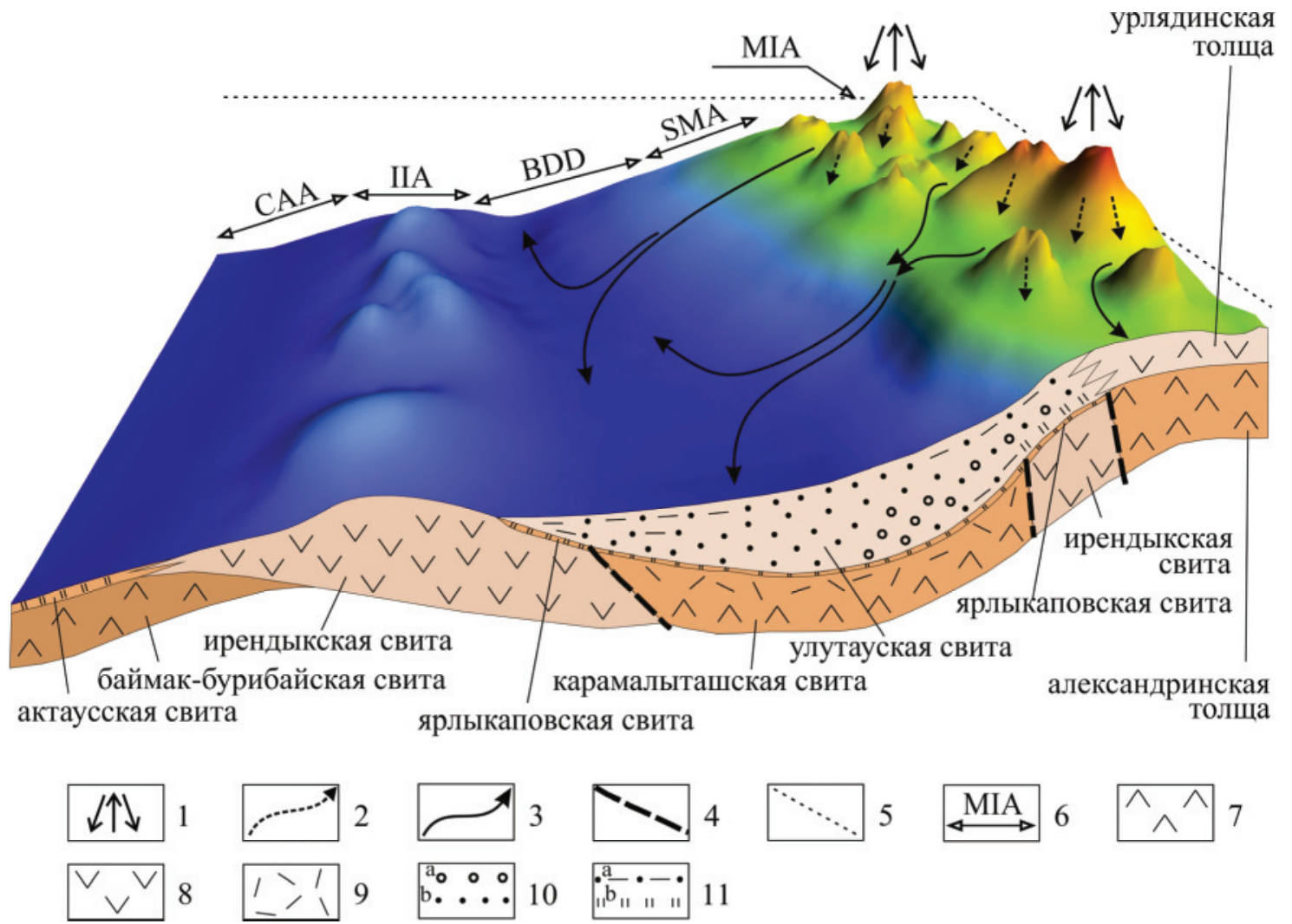

Pис. 1. Реконструкиия живетско-раннефранского бассейна Магнитогорской островной дуги по [9]. Условные обозначения: 1) эксплозии и оседание пирокластики, 2) разлыв вулканических аппаратов, 3) гравитационные потоки, осуществившие перенос кластики в глубоководные области; 4) предполагаемые разрывные дислокации; 5) уровня моря; 6) зоны внутри бассейна: МIA - активная Магнитогорская островная дуга, SMA - глубоководный склон, BDD - ложе глубоководной впадины, IIA - потухшая Ирендыкская островная дуга, САA - зона крелненакопления; 7) базальты; 8) андезиты и андезибазальты; 9 ) риолиты и даииты; 10) грубообломочные кластолиты (a) и песчаники (b);11) алевролиты (a), кремни и ящлы (b)

Fig. 1. Reconstruction of the Givetian - Early Frasnian basin of the Magnitogorsk island arc according to [9]. Legend: 1) explosions and accumulation of pyroclastics, 2) clastic flow during destruction of volcanos, 3) sedimentary gravity flows moving to deep-water zones; 4 ) alleged faults; 5 ) sea level; 6 ) zones within the basin: MIA - active Magnitogorsk island arc, SMA - slope of Magnitogorsk island arc, $B D D$ - bottom of the deepwater depression, IIA - extinct Irendyk island arc, CAA-chert-accumulation area; 7) basalts; 8) andesites and andesibasalts; 9 ) rhyolites and dacites; 10$)$ coarse grained sediments $(a)$ and sandstones $(b) ; 11)$ siltstone (a), cherts and jasper (b) 
Областям вулканизма Магнитогорской островной дуги в живетско-раннефранское время и, соответственно, питающей провинции кластолитов улутауской свиты отвечает урлядинская толща $[11,13,14]$. Она сложена эффузивами и туфами от основного до кислого состава [7]. Мощность их от 80 до 1300 м.

Магнитогорская островная дуга, согласно [15-17], являлась энсиматической.

\section{Фактический материал и методика работ}

В основе работы лежат 202 определения содержания породообразующих элементов методами "мокрой» химии (ИГ УФИЦ РАН, аналитик C.А. Ягудина) в граувакках улутауской свиты из коллекции автора. Результаты силикатного анализа вулканитов урлядинской толщи общим количеством 202 пробы собраны из фондовых работ разных лет сотрудниками АО «Челябинскгеолсъемка» и любезно предоставлены В.М. Мосейчуком (000 НПП «Геопоиск», г. Челябинск).

Для дальнейшего анализа граувакки были поделены на две группы по содержанию кремнезема: кислые вулканокластические граувакки (52 образца) с концентрацией $\mathrm{SiO}_{2}$ более $63 \%$ и основные вулканокластические граувакки (150 образцов) - $\mathrm{SiO}_{2}$ менее $63 \%$. Граница, равная $63 \%$, была установлена в соответствии с [18]. Вулканиты подразделены на 4 категории: риолиты и риодациты $\left(\mathrm{SiO}_{2}\right.$ более $69 \%, 80$ образцов), дациты $\left(\mathrm{SiO}_{2}\right.$ 63-69 \% , 44 образца), андезиты и андезибазальты $\left(\mathrm{SiO}_{2} 52-63 \%, 44\right.$ образца) и базальты $\left(\mathrm{SiO}_{2}\right.$ 45-52\%, 34 образца). Граничные содержания $\mathrm{SiO}_{2}$ для перечисленных вулканитов заимствованы из [19].

При проведении анализа диаграмм на них выносились фигуративные точки состава пород. В дальнейшем подсчитывалось количество точек каждой из выделенных групп, попавшее в те или иные поля диаграмм, и рассчитывалась их доля в процентах от общего количества проб группы.

\section{Результаты построения диаграмм}

Диагралла Дж. Мейнарда $\mathrm{K}_{2} \mathrm{O} / \mathrm{Na}_{2} \mathrm{O}-\mathrm{SiO}_{2} / \mathrm{Al}_{2} \mathrm{O}_{3}$ (рис. 2, б) [20, 21]. В поле островодужных кластолитов андезитового и базальтового состава попало подавляющее большинство точек основных вулканокластических граувакк $(95 \%)$, базальтов $(91 \%)$, андезитов (77\%), дацитов $(72 \%)$, в меньшей мере - кислых вулканокластических граувакк $(46 \%)$ и риолитов $(28 \%)$. В полях окраин андского типа и островодужных осадков с преобладанием кластики кислых магматических образований расположились точки кислых граувакк $(48 \%)$, риолитов $(51 \%)$ и дацитов $(10 \%)$.

Диагралма Б. Розера и Р. Корша $\mathrm{SiO}_{2}-\mathrm{K}_{2} \mathrm{O} / \mathrm{Na}_{2} \mathrm{O}$ (рис. $2, a)$ [21]. В поле энсиматических островных дуг оказалось большая часть точек, отвечающих основным вулканокластическим грауваккам (99\%), базальтам (97\%), андезитам (80\%), а также менее значимое количество точек кислых вул- канокластических граувакк (31\%). По соотношению кремнезема и щелочей кислые разности соответствуют в большей мере отложениям окраин андского типа: граувакки на $68 \%$, дациты - на $55 \%$ и риолиты - на $85 \%$.

Факторная диагралла M. Бхатии F1-F2 (рис. 2, в) [22]. В поле энсиматических островных дуг расположились точки основных граувакк $(66 \%)$, базальтов (97\%) и андезитов (68 \%). Риолиты $(41 \%)$, дациты (73\%) и граувакки кислого состава $(60 \%)$ в большинстве своем заняли позиции в полях энсиалических дуг и окраин андского типа.

Диаграмлы DF1-DF2 C. Верла и Дж. Арлстронга-Алтрина (рис. 2, г, )) [18] существуют в двух вариантах - отдельно для кислых и основных граувакк. Граница между этими разностями установлена авторами диаграммы по содержанию кремнезема в $63 \%$.

На диаграммы DF1-DF2 и для кислых, и для основных разностей были вынесены точки всех рассматриваемых пород. Их подавляющее большинство, независимо от содержания кремнезема, расположилось в поле островодужных обстановок.

Диагралмы М. Бхатии (не факторные) (рис. $3, a-2$ ) [22] в своей основе имеют пять параметров. Первый - $\mathrm{Fe}_{2} \mathrm{O}_{3}+\mathrm{MgO}$ является общим для всех диаграмм и откладывается по оси абсцисс, остальные четыре - индивидуальны для каждой диаграммы и откладываются по оси ординат: $\mathrm{Al}_{2} \mathrm{O}_{3} / \mathrm{SiO}_{2}, \mathrm{~K}_{2} \mathrm{O} / \mathrm{Na}_{2} \mathrm{O}, \mathrm{Al}_{2} \mathrm{O}_{3} /\left(\mathrm{CaO}+\mathrm{Na}_{2} \mathrm{O}\right)$ и $\mathrm{TiO}_{2}$. Xaрактеристика каждой из четырех диаграмм избыточна, поэтому ниже будут охарактеризованы вкратце и по отдельности лишь параметры, заложенные в их основу.

Основные вулканокластические граувакки улутауской свиты соответствуют осадкам акваторий энсиматических островных дуг по величинам $\mathrm{TiO}_{2}, \quad\left(\mathrm{Fe}_{2} \mathrm{O}_{3}+\mathrm{MgO}\right), \quad \mathrm{Al}_{2} \mathrm{O}_{3} / \mathrm{SiO}_{2}, \quad \mathrm{~K}_{2} \mathrm{O} / \mathrm{Na}_{2} \mathrm{O} \quad$ и $\mathrm{Al}_{2} \mathrm{O}_{3} /\left(\mathrm{CaO}+\mathrm{Na}_{2} \mathrm{O}\right)$ на $13,85,100,92$ и $99 \%$, соответственно. По двум последним отношениям этой же геодинамической позиции более чем на $90 \%$ соответствуют и кислые вулканокластические граувакки, но по величинам $\mathrm{Al}_{2} \mathrm{O}_{3} / \mathrm{SiO}_{2}$ и $\mathrm{TiO}_{2}$ они близки к осадкам энсиалических островных дуг, окраин андского типа и отчасти даже пассивным окраинам континентов.

Базальты урлядинской толщи по величинам $\left(\mathrm{Fe}_{2} \mathrm{O}_{3}+\mathrm{MgO}\right), \mathrm{Al}_{2} \mathrm{O}_{3} / \mathrm{SiO}_{2}, \mathrm{~K}_{2} \mathrm{O} / \mathrm{Na}_{2} \mathrm{O}$ и $\mathrm{Al}_{2} \mathrm{O}_{3} /\left(\mathrm{CaO}+\mathrm{Na}_{2} \mathrm{O}\right)$ более чем на $90 \%$ сопоставимы с осадками энсиматических островных дуг. К этой же категории, но лишь по величинам $\mathrm{K}_{2} \mathrm{O} / \mathrm{Na}_{2} \mathrm{O}$ и $\mathrm{Al}_{2} \mathrm{O}_{3} /\left(\mathrm{CaO}+\mathrm{Na}_{2} \mathrm{O}\right)$ приближаются риолиты и дациты: их состав соответствует осадкам акваторий энсиматических дуг от 73 до $95 \%$, тогда как по величинам $\left(\mathrm{Fe}_{2} \mathrm{O}_{3}+\mathrm{MgO}\right), \mathrm{Al}_{2} \mathrm{O}_{3} / \mathrm{SiO}_{2}, \mathrm{TiO}_{2}$ он близок к осадкам других геодинамических обстановок.

\section{Обсуждение}

Попытки разработать универсальные методы диагностики условий формирования осадков и ос- 
a

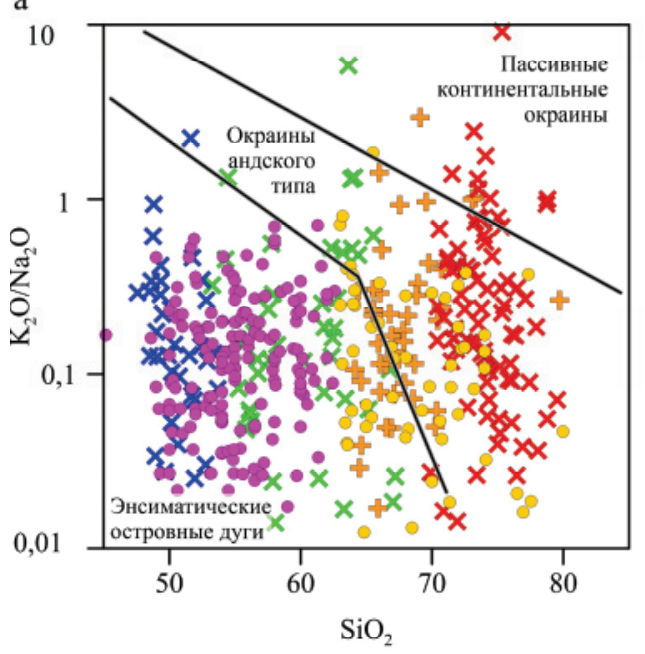

B
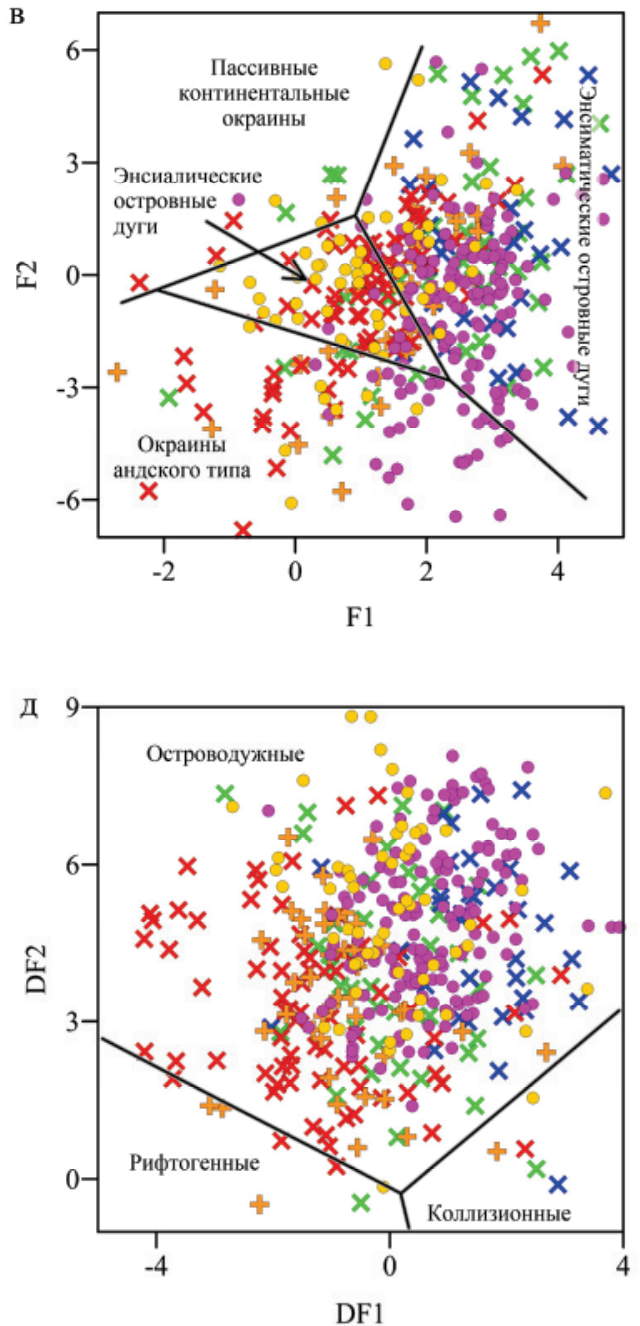

6

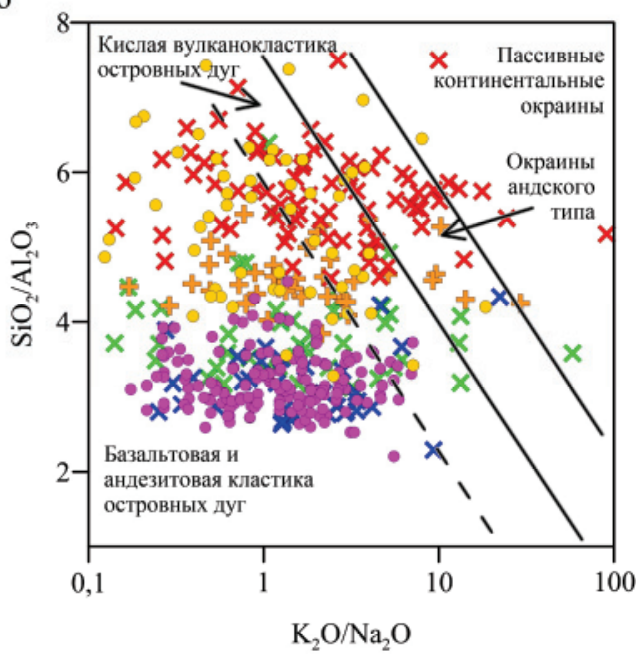

$\Gamma$

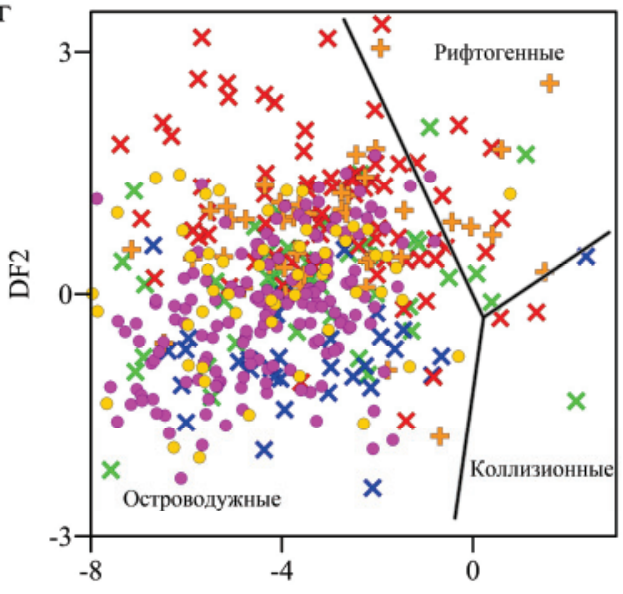

DF1

Рис. 2. Геодинамические диаграмлы для граувакк улутауской свиты и вулканитов урлядинской толщи: а) диаграмма $\mathrm{SiO}_{2}-\mathrm{K}_{2} \mathrm{O} / \mathrm{Na}_{2} \mathrm{O}$ nо [21], б) диаграмла $\mathrm{K}_{2} \mathrm{O} / \mathrm{Na}_{2} \mathrm{O}-\mathrm{SiO}_{2} / \mathrm{Al}_{2} \mathrm{O}_{3}$ по $[20,21]$, в) факторная диаграмма F1-F2 по [22], г, д) факторные диаграммы DF1-DF2 по [18], предназначенные для осадков с низким (2) и высоким (ә) содержанием кремнезема. Условные обозначения: 1-2 - граувакки улутауской свиты: 1 - основные, 2 - кислье; 3-6 - эффузивы урлядинской толщи: 3- риолиты и риодащиты, 4 - дащиты, 5 -андезиты, 6 - андезибазальты и базальты

Fig. 2. Geodynamic diagrams for graywackes of the Ulutau formation and volcanic rocks of the Urlyada formation: a) diagram $\mathrm{SiO}_{2}-\mathrm{K}_{2} \mathrm{O} / \mathrm{Na}_{2} \mathrm{O}$ after [21], б) $\mathrm{SiO}_{2}-\mathrm{K}_{2} \mathrm{O} / \mathrm{Na}_{2} \mathrm{O}$ diagram after [20, 21], в) factor diagram $\mathrm{F} 1-\mathrm{F} 2$ after [22], 2, d) factor diagrams DF1-DF2 after [18], intended for precipitation with low (2) and high (2) silica graywackes. Legend: 1-2 - Ulutau formation greywackes: 1 - low-silica, 2-high-silica; 3-6-volcanic rocks of the Urlyada formation: 3 -rhyolites and rhyodacites, 4-dacites, 5 -andesites, 6 - andesibasalts and basalts 

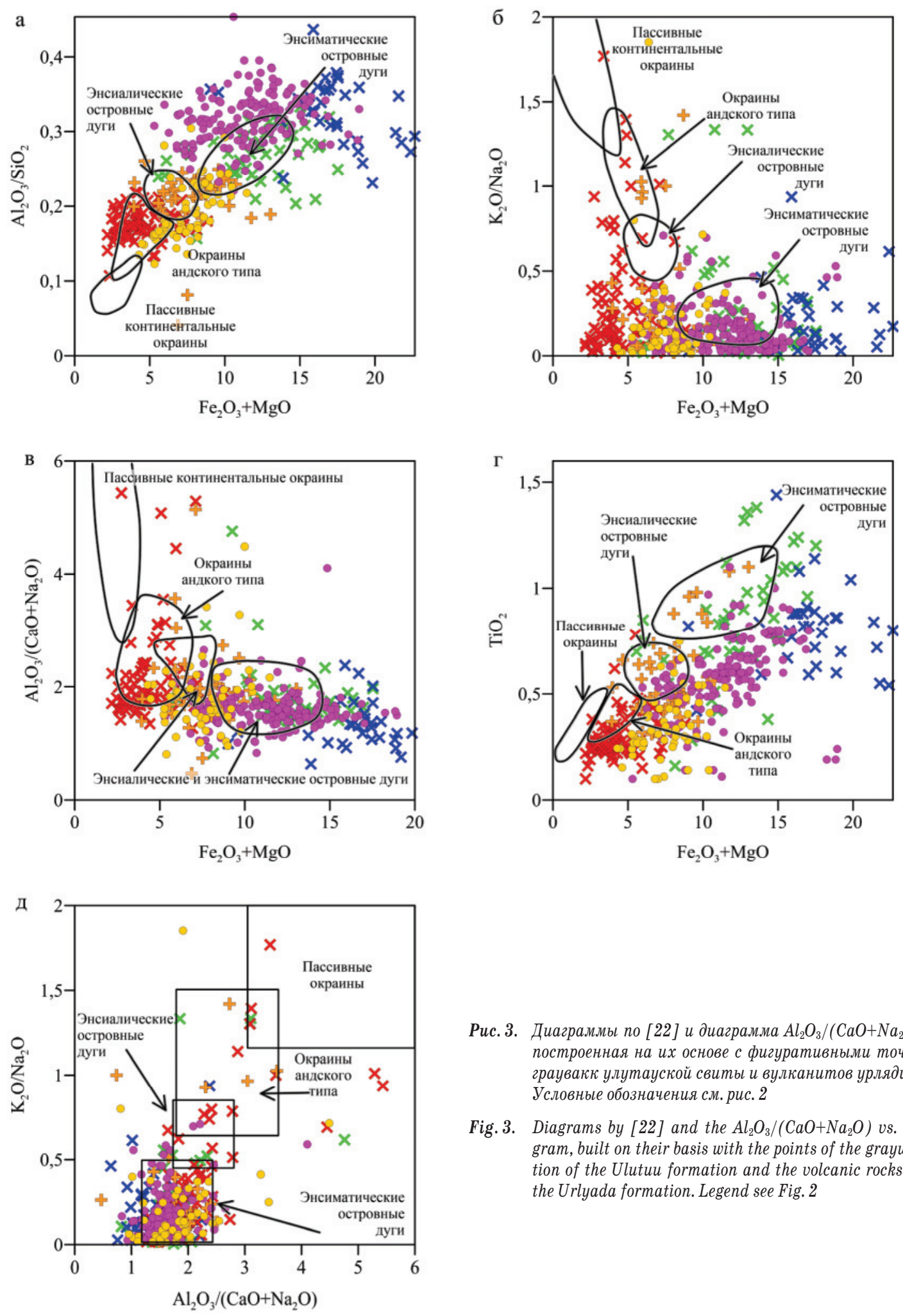

Puc. 3. Диаграмлы по [22] и диаграмма $\mathrm{Al}_{2} \mathrm{O}_{3} /\left(\mathrm{CaO}+\mathrm{Na}_{2} \mathrm{O}\right)-\mathrm{K}_{2} \mathrm{O} / \mathrm{Na}_{2} \mathrm{O}$, построенная на их основе с фигуративными точками состава граувакк улутауской свиты и вулканитов урлядинской толщи. Условные обозначения см. рис. 2

Fig. 3. Diagrams by [22] and the $\mathrm{Al}_{2} \mathrm{O}_{3} /\left(\mathrm{CaO}+\mathrm{Na}_{2} \mathrm{O}\right)$ vs. $\mathrm{K}_{2} \mathrm{O} / \mathrm{Na}_{2} \mathrm{O}$ diagram, built on their basis with the points of the graywackes composition of the Ulutuu formation and the volcanic rocks composition of the Urlyada formation. Legend see Fig. 2

адочных пород на основе петрографических, геохимических, геофизических и других данных, на подобие рассмотренных геодинамических диаграмм, предпринимаются уже на протяжении многих десятилетий. В большинстве своем, после опробования на практике, универсальность их по-

степенно утрачивается. Причины этого подробно раскрыты В.Н. Швановым [23] на примере генетических гранулометрических диаграмм. Эти причины, по всей видимости, справедливы для всех случаев и заключаются, в частности, в том, что свойства осадков и осадочных пород зависят от множе- 
ства факторов, а не только от тех, что «присутствуют» на диаграммах. Кроме этого, в седиментогенезе (в широком смысле) решающую роль играют местные условия, а это и обусловливает различия осадков, сформированных в близких палеогеографических, геодинамических и прочих обстановках, но в разных районах и в разное время. Тем не менее, по мнению В.Н. Шванова, генетические диаграммы могут оказаться полезными, если анализировать расположение точек исследуемых проб друг относительно друга, а не только относительно эталонных полей.

Прямая и обратная связи состава осадков с условиями их формирования должны изучаться, а выявленные закономерности, представленные в том числе в виде генетических диаграмм, непременно должны учитываться и применяться при реконструкциях.

Первым, на что важно обратить внимание, является соответствие действительным геодинамическим обстановкам состава основных вулканокластических граувакк и вулканитов аналогичного состава - андезитов и базальтов. Кислые разности граувакк, риолиты и дациты имеют литохимические характеристики, преимущественно свойственные, исходя из представленных диаграмм, осадкам иных геодинамических обстановок, вплоть до пассивных континентальных окраин. Следовательно, тефрогенные песчаники, в составе которых присутствуют кислые вулканиты, менее приемлемы для генетического анализа на основе большинства диаграмм.

Исключением можно считать лишь отношения $\mathrm{K}_{2} \mathrm{O} / \mathrm{Na}_{2} \mathrm{O}$ и $\mathrm{Al}_{2} \mathrm{O}_{3} /\left(\mathrm{CaO}+\mathrm{Na}_{2} \mathrm{O}\right)$, поскольку в кислых граувакках и вулканитах они близки к значениям, установленным М. Бхатией для отложений акваторий энсиматических островных дуг. Представляется целесообразным вынести их на отдельную диаграмму (рис. 3, ә). Как видно, подавляющее большинство точек, отвечающих составу и кислых, и основных граувакк и вулканитов, расположилось в поле энсиматических островных дуг.

Второй особенностью, выявленной при построении диаграмм, является то, что кластеры граувакк и вулканитов практически совпадают. Следовательно, состав кластолитов не претерпел существенной трансформации при мобилизации, транспортировке и аккумуляции. Данное заключение подтверждает ранее сделанный вывод о лавинной скорости седиментации отложений улутауской свиты [12]. Помимо этого, представляется важным, что кластеры граувакк являются более компактными, по сравнению с кластерами вулканитов. По всей видимости, это объясняется смешением зерен разных вулканитов и, таким образом, приближением состава граувакк к некоторым «усреднённым» параметрам.

Интересно отметить, что на многих диаграммах кластер основных граувакк мало пересекается с кластером базальтов. Вероятно, это обусловлено низкой эксплозивностью базальтовых магм и, со- ответственно, небольшим количеством кластики, мобилизуемой при их извержении.

Исследования, близкие по своему направлению к тем, что изложены здесь, проводились неоднократно. К примеру, А.В. Масловым с коллегами [24] показано, что диаграммы Бхатии являются относительно приемлемыми для граувакковых отложений приостроводужных областей, тогда как для отложений платформенных и субплатформенных зон (кварцевые, полевошпат-кварцевые и аркозовые песчаники) наиболее пригодны диаграммы Мейнарда и Розера-Корша. Согласно [25], сомнительно применение параметров, в расчет которых входят $\mathrm{K}_{2} \mathrm{O}$ и $\mathrm{Na}_{2} \mathrm{O}$ из-за высокой подвижности этих элементов, а также отмечены положительные результаты применения диаграммы $\left(\mathrm{Fe}_{2} \mathrm{O}_{3}+\mathrm{MgO}\right)-\mathrm{TiO}_{2}$ по [22].

Как следует из наших данных, применение диаграмм Мейнарда и Розера-Корша для островодужных отложений дает хорошие результаты, а диаграммы $\left(\mathrm{Fe}_{2} \mathrm{O}_{3}+\mathrm{MgO}\right)-\mathrm{TiO}_{2}$, - отрицательные: в поле энсиматических дуг попало всего $13 \%$ основных граувакк, а по отношениям $\mathrm{K}_{2} \mathrm{O} / \mathrm{Na}_{2} \mathrm{O}$ и $\mathrm{Al}_{2} \mathrm{O}_{3} /\left(\mathrm{CaO}+\mathrm{Na}_{2} \mathrm{O}\right)$ энсиматическим островным дугам соответствуют не только основные разности, но и кислые. Таким образом, наши результаты не согласуются с результатами [24, 25]. Очевидно, эти несоответствия в очередной раз показывают, что все геологические объекты уникальны. Изучение каждого из них требует индивидуального подхода, а слепое применение «универсальных» методов может привести к ошибочным выводам.

В завершении интересно отметить, что помимо объективных причин, обусловливающих получение спорных результатов построения геодинамических диаграмм, могут оказаться решающими и субъективные факторы. При многократном копировании из статьи в статью неминуемо появляются искажения полей диаграмм и ошибки в формулах. Например, формулы расчета дискриминантных функций DF1 и DF2 в статье [26] отличаются от первоисточника [22]. Также не совпадают формулы дискриминантной функции $\mathrm{DF}_{(\mathrm{A-P)M}}$ в работе [27] и в первоисточнике [28], при этом верным является первый вариант!

\section{Выводы}

Сравнительный анализ положения фигуративных точек состава тефрогенных граувакк улутауской свиты и вулканогенных пород урлядинской толщи, соответствующих их источнику сноса, сформированных в пределах энсиматической Магнитогорской островной дуги, позволил прийти к следующим результатам.

1) Применение основных вулканокластических граувакк $\mathrm{SiO}_{2}<63 \%$ для построения геодинамических диаграмм позволяет достичь более реалистичных результатов. Точки состава кислых вулканокластических граувакк, риолитов и дацитов, сформированных в пределах энсиматической островной дуги, в большинстве своем попадают в поля энсиалических остров- 
ных дуг, окраин андского типа и отчасти пассивных континентальных окраин.

2) Поля граувакк практически совпадают с полями вулканитов на большинстве диаграмм. Это подтверждает ранее сделанный вывод о высокой скорости накопления отложений улутауской свиты.

3) Поля граувакк, занимаемые на диаграммах, являются более компактными по сравнению с полями вулканитов, что объясняется некоторым смешением (усреднением состава) кластики, а также невысокой эксплозивностью базальтовых магм.

4) Большинство проанализированных диаграмм (Мейнарда, Розера-Корша, Бхатии, Верма и Армстронга-Алтрина) может успешно применяться при изучении основных вулканокластических граувакк. Исключением служат диаграмма Бхатии $\left(\mathrm{Fe}_{2} \mathrm{O}_{3}+\mathrm{MgO}\right)-\mathrm{TiO}_{2}$, на которой большинство точек и вулканитов, и песчаников не попало в какое-либо поле.

5) Для изучения кислых вулканокластических граувакк могут быть использованы диаграммы

\section{СПИСОК ЛИТЕРАТУРЫ}

1. Зайнуллин Р.И. Состав и особенности формирования вулканокластических отложений нижнего девона Западно-Магнитогорской зоны Южного Урала // Литосфера. - 2017. - Т. 17. № 2. - C. 78-94.

2. Мельничук 0.Ю., Рянская А.Д. Особенности вещественного состава аргиллитов кодинской свиты (верхний девон, восток Среднего Урала) // Литосфера. - 2017. - Т. 17. - № 3. C. $71-86$.

3. Syn-rift sandstones: the features of bulk chemical compositions, and positions on paleogeodynamic discriminant diagrams / A.V. Maslov, V.N. Podkovyrov, E.Z. Gareev, N.D. Sergeeva // Geodynamics and tectonophysics. - 2018. - V. 9. - № 1. P. 59-80.

4. Tectonic setting discrimination diagrams for terrigenous rocks: a comparison / A.V. Maslov, V.N. Podkovyrov, G.A. Mizens, A.D. Nozhkin, A.M. Fazliakhmetov, A.I. Malinovsky, A.K. Khudoley, L.N. Kotova, A.V. Kuptsova, E.Z. Gareev, R.I. Zainullin // Geochemistry International. - 2016. - V. 54. - № 7. P. 569-583.

5. Geochemistry of deep-sea sediments in two cores retrieved at the mouth of the Coatzacoalcos River delta, western Gulf of Mexico, Mexico / M.A. Ramos-Vázquez, J.S. Armstrong-Altrin, L. Rosales-Hoz, M.L. Machain-Castillo, A. Carranza-Edwards // Arabian Journal of Geosciences. - 2017. - 10:148.

6. Terrestrial deposition processes of Quaternary gibbsite nodules in the Yongjiang Basin, southeastern margin of Tibet, and implication for the genesis of ancient karst bauxite / S. Yang, Q. Wang, Q. Zhang, J. Chen, Y. Huang // Sedimentary Geology. - 2018. № 373. - P. 292-306.

7. Маслов В.А., Артюшкова 0.В. Стратиграфия и корреляция девонских отложений Магнитогорской мегазоны Южного Урала. - Уфа: ДизайнПолиграфСервис, 2010. - 288 с.

8. Мизенс Г.А. Средне- и верхнепалеозойские обломочные породы юга Урала как индикаторы палеотектонических и палеогеодинамических обстановок // Литология и геология горючих ископаемых. - Екатеринбург: Изд-во Уральского государственного горного университета, 2008. - Вып. II. - № 18. C. $183-195$.
DF1-DF2 по [18] и «модифицированная» диаграмма М. Бхатии $\mathrm{Al}_{2} \mathrm{O}_{3} /\left(\mathrm{CaO}+\mathrm{Na}_{2} \mathrm{O}\right)-\mathrm{K}_{2} \mathrm{O} / \mathrm{Na}_{2} \mathrm{O}$. Построение прочих диаграмм дало противоречивые результаты: большинство точек оказалось в полях, не отвечающих существовавшим в действительности геодинамическим обстановкам.

6) Результаты, полученные при построении литохимических диаграмм, нельзя считать окончательными. Желательно дополнять их другими методами. Особенно это важно при изучении кластолитов, в составе которых присутствуют вулканиты кислого состава.

Исследования выполнены по теме государственного задания № 0246-2019-0118.

Автор признателен д.г.м.н.Виктору Алексеевичу Маслову за демонстращию большинства опробованных разрезов и Валерию Михайловичу Мосейчуку за предоставленные данные по вулканитам урлядинской толщи. Особая благодарность выражается Саиде Ахметсаитовне Ягудиной аналитику хилической лаборатории ИГ УФИЦ РАН, за выполнение силикатного анализа по всем использованным образиам улутауской свиты.

9. Фазлиахметов А.М. Условия седиментации улутауской свиты Западно-Магнитогорской зоны Южного Урала // Литосфера. 2011. - № 2. - С. 42-52.

10. Широбокова Т.И. Петрохимические и геохимические особенности фаций среднедевонских обломочных пород Баймакского района // Палеовулканизм Урала. - Свердловск: УНЦ АН CCCP, 1975. - C. 193-202.

11. Маслов В.А., Артюшкова 0.В., Барышев В.Н. Стратиграфия рудовмещающих девонских отложений Сибайского района. Уфа: БФАН СССР, 1984. - 100 c.

12. Фазлиахметов А.М. 0 причинах лавинной седиментации улутауской свиты Западно-Магнитогорской зоны Южного Урала // Вестник Института геологии Коми НЦ. - 2011. - № 1. - С. 19-21.

13. Артюшкова 0.В., Маслов В.А. Палеонтологическое обоснование стратиграфического расчленения дофаменских вулканогенных комплексов Верхнеуральского и Магнитогорского районов. - Уфа: ИГ УфНЦ РАН, 1998. - 156 с.

14. Мизенс Г.А., Свяжина И.А. 0 палеогеографии Урала в девоне // Литосфера. - 2007. - № 2. - С. 29-44.

15. Вулканизм Южного Урала / И.Б. Серавкин, А.М. Косарев, Д.Н. Салихов, С.Е. Знаменский, З.И. Родичесва, М.В. Рыкус, В.И. Сначев. - М.: Наука, 1992. -197 с.

16. Язева Р.Г., Бочкарев В.В. Геология и геодинамика Южного Урала: (Опыт геодинамического картирования). - Екатеринбург: ИГГ Ур0 РАН, 1998. - 203 с.

17. Косарев А.М., Пучков В.Н., Серавкин И.Б. Петролого-геохимические особенности среднедевонско-раннекаменноугольных островодужных и коллизионных вулканитов Магнитогорской зоны в геодинамическом контексте // Литосфера. - 2006. № 1. - C. 3-21.

18. Verma S.P., Armstrong-Altrin J.S. New multi-dimensional diagrams for tectonic discrimination of siliciclastic sediments and their application to Precambrian basins // Chemical Geology. 2013. - № 355. - P. 117-133.

19. Петрографический кодекс. Магматические, метаморфические, метасоматические, импактные образования / под ред. О.А. Богатикова, О.В. Петрова. - СПб: ВСЕГЕИ, 2008. - 200 с.

20. Maynard J.B., Valloni R., Ho Shing Ju. Composition of modern deep-sea sands from arc-related basin // Geological Society London Special Publications. - 1982. - V. 10. - № 1. - P. 551-561. 
21. Roser B.P., Korsch R.J. Determination of tectonic settings of sandstone-mudstone suits using $\mathrm{SiO}_{2}$ content and $\mathrm{K}_{2} \mathrm{O} / \mathrm{Na}_{2} \mathrm{O}$ ratio // Journal of Geology. - 1986. - V. 94 - № 5. - P. 635-650.

22. Bhatia M.R. Plate tectonic and geochemical composition of sandstones // Journal of Geology. - 1983. - № 91. - P. 611-627.

23. Шванов В.Н. Песчаные породы и методы их изучения. - Л.: Недра, 1969. - 248 с.

24. Маслов А.В., Гареев Э.З., Ишерская М.В. «Стандартные» дискриминантные палеогеодинамические диаграммы и платформенные песчаниковые ассоциации // Отечественная геология. - 2012. - № 3. - С. 55-65.

25. Ryan K.M., Williams D.M. Testing the reliability of discrimination diagrams for determining the tectonic depositional environment of ancient sedimentary basins // Chemical Geology. 2007. - № 242. - P. 103-125.
26. Armstrong-Altrin J.S., Verma S.P. Critical evaluation of six tectonic setting discrimination diagrams using geochemical data of Neogene sediments from known tectonic settings // Sedimentary Geology. - 2005. - № 177. - P. 115-129.

27. Zaid S.M. Petrography and geochemistry of the Middle Miocene Gebel El Rusas sandstones, Eastern Desert, Egypt: Implications for provenance and tectonic setting // Journal of Earth System Science. - 2017. - 126:103.

28. Verma S.P., Armstrong-Altrin J.S. Geochemical discrimination of siliciclastic sediments from active and passive margin settings // Sedimentary Geology. - 2016. - № 332. - P. 1-12.

Поступила 18.10.2018 2.

\section{Информация об авторах}

Фазлиахметов A.M., кандидат геолого-минералогических наук, старший научный сотрудник Лаборатории стратиграфии палеозоя Института геологии - обособленного структурного подразделения Уфимского федерального исследовательского центра Российской академии наук. 


\title{
ON APPLICATION OF GEODYNAMIC LITHOCHEMICAL DIAGRAMS IN STUDYING TEFROGENIC SANDSTONES
}

\author{
Alexandr M. Fazliakhmetov, \\ famrb@mail.ru \\ Institute of Geology - Subdivision of the Ufa Federal Research Centre of the Russian Academy of Sciences, \\ 16/2, Karl Marks street, Ufa, 450077, Russia.
}

The relevance. Diagrams that allow assuming the geodynamic position of sedimentary basins on the basis of lithochemical features of clastoliths have been used for many decades. At the same time, the possibility of using them to study tefrogenic sandstones is not clear, and the results are contradictory.

The main aim of the research is a comparative analysis of the position on the most frequently used point diagrams corresponding to the composition of two groups of rocks - tefrogenic sandstones and volcanic rocks of their source.

Objects of the research are tephrogenic greywackes of the Ulutau formation and volcanic rocks (from rhyolites to basalts) of the Urlada formation of the Magnitogorsk megazone of the Southern Urals. Age of Ulutau formation is the Givetian - Early Frasnian. Genetically greywackes are tephrogenic turbidites and debrites, formed in the deep-water depression located at the foot of the oceanic Magnitogorsk island arc. In the modern erosional slice the axial zone of the island arc corresponds to the volcanics of the Urlada formation. Methods. The comparison is based on the results of determination of the main elements content in the Ulutau formation greywackes (202 samples) and Urlada formation volcanics (202 samples). The comparison was made on the basis of the Meinard, Bhatia, Roser-Korsch and Verma-Armstrong-Altrin diagrams.

Results. The analysis of the diagrams showed that the use of the low silica volcaniclastic greywackes $\left(\mathrm{SiO}_{2}<63 \%\right)$ gives more realistic results. An exception in this case is the diagram $\left(\mathrm{Fe}_{2} \mathrm{O}_{3}+\mathrm{MgO}\right)-\mathrm{TiO}_{2}$ : most of the points turned out to be outside of any fields. Hi-silica graywackes with $\left(\mathrm{SiO}_{2}>63 \%\right)$ in many diagrams fall into the fields of oceanic island arcs, active and passive continental margins. The best results for Hi-silica rocks were obtained using the DF1-DF2 diagram and the modified Bhatia $\mathrm{Al}_{2} \mathrm{O}_{3} /\left(\mathrm{CaO}+\mathrm{Na}_{2} \mathrm{O}\right)-\mathrm{K}_{2} \mathrm{O} / \mathrm{Na}_{2} \mathrm{O}$ diagram. The fields of greywacke on the majority of diagrams coincide with the fields of volcanic rocks and are more compact compared to them, which is caused by the mixed composition of sandstones and low explosiveness of basalt melts. The results obtained are largely not consistent with the results of similar studies. Consequently, the conclusions obtained when constructing lithochemical geodynamic diagrams cannot be considered as the final ones and must be supplemented by other methods.

\section{Key words:}

Geodynamic diagrams, sandstones, greywackes, oceanic island arc, the Devonian, the Magnitogorsk megazone, the Southern Urals.

Studies have been carried out on the state assignment number 0252-2014-0003.

The author is grateful to Dr. Sc. Victor A. Maslov for demonstration of the majority of the tested sections and to Valeri M. Moseychuk for the data provided on the volcanic rocks of the Urlyada formation. Special thanks are expressed to Saida A. Yagudina, analyst at the chemical laboratory of the IG UFRC RAS, for performing analysis on all the used samples of the Ulutau formation.

\section{REFERENCES}

1. Zainullin R.I. Composition and distinctive features of Lower Devonian volcaniclastic sediments formation of the West-Magnitogorsk zone, the Southern Urals. Lithosphere, 2017, vol. 17, no. 2, pp. 78-94. In Rus.

2. Melnichuk 0.Yu., Ryanskaya A.D. Specific composition features of Kodinka formation mudstones (Upper Devonian, Middle Urals eastern slope). Lithosphere, 2017, vol. 17, no. 3, pp. 71-86. In Rus.

3. Maslov A.V., Podkovyrov V.N., Gareev E.Z., Sergeeva N.D. Synrift sandstones: the features of bulk chemical compositions, and positions on paleogeodynamic discriminant diagrams. Geodyna mics and tectonophysics, 2018, vol. 9, no. 1, pp. 59-80.

4. Maslov A.V., Podkovyrov V.N., Mizens G.A., Nozhkin A.D., Fazliakhmetov A.M., Malinovsky A.I., Khudoley A.K., Kotova L.N., Kuptsova A.V., Gareev E.Z., Zainullin R.I. Tectonic setting discrimination diagrams for terrigenous rocks: a comparison. Geochemistry International, 2016, vol. 54, no. 7, pp. 569-583.

5. Ramos-Vázquez M.A., Armstrong-Altrin J.S., Rosales-Hoz L., Machain-Castillo M.L., Carranza-Edwards A. Geochemistry of deep-sea sediments in two cores retrieved at the mouth of the $\mathrm{C}_{0}$ atzacoalcos River delta, western Gulf of Mexico, Mexico. Arabian Journal of Geosciences, 2017, 10:148.

6. Yang S., Wang Q., Zhang Q., Chen J., Huang Y. Terrestrial deposition processes of Quaternary gibbsite nodules in the Yongjiang
Basin, southeastern margin of Tibet, and implication for the genesis of ancient karst bauxite. Sedimentary Geology, 2018, no. 373 , pp. 292-306.

7. Maslov V.A., Artyushkova 0.V. Stratigrafiya i korrelyatsiya devonskikh otlozheniy Magnitogorskoy megazony Yuzhnogo Urala [Stratigraphy and correlation of the Devonian deposits of the Magnitogorsk megazone of the Southern Urals]. Ufa, DesignPoligraphService Publ., 2010. 288 p.

8. Mizens G.A. Sredne- i verkhnepaleozoyskiye oblomochnyye porody yuga Urala kak indikatory paleotektonicheskikh i paleogeodinamicheskikh obstanovok [Middle and Upper Paleozoic detrital rocks of the south of the Urals as indicators of paleotectonic and paleogeodynamic settings]. Litologiya i geologiya goryuchikh iskopayemykh [Lithology and geology of combustible minerals]. Ekaterinburg, Ural State Mining University Publ. house, 2008. Vol. 2, no. 18. pp. 183-195.

9. Fazliahmetov A.M. Sedimentary environments of the Ulutau suite in the West-Magnitogorsk zone of the South Urals. Lithosphere, 2011, no. 2, pp. 42-52. In Rus.

10. Shirobokova T.I. Petrokhimicheskie i geokhimicheskie osobennosti fatsiy srednedevonskikh oblomochnykh porod Baymakskogo rayona [Petrochemical and geochemical features of the facies of the Middle Devonian clastic rocks of the Baymak region]. Paleovulkanizm Urala [Paleovolcanology of the Urals]. Sverdlovsk, UC USSR Academy of Sciences Publ., 1975. pp. 193-202. 
11. Maslov V.A., Artyushkova 0.V., Baryshev V.N. Stratigrafiya rudoumeshchayushchikh devonskikh otlozheniy Sibayskogo rayona [Stratigraphy of ore-bearing Devonian deposits of Sibay district]. Ufa, BFAN USSR Publ., 1984. $100 \mathrm{p}$.

12. Fazliahmetov A.M. About reasons of avalanche sedimentation of the Ulutau formation in the West-Magnitogorsk zone of the Southern Urals. Bulletin of the Institute of Geology of the Komi Scientific Center, 2011, no. 1, pp. 19-21. In Rus.

13. Artyushkova 0.V., Maslov V.A. Paleontologicheskoe obosnovanie stratigraficheskogo raschleneniya dofamenskikh vulkanogennykh kompleksov Verkhneuralskogo i Magnitogorskogo rayonou [Paleontological substantiation of the stratigraphic dismemberment of the prefamenian volcanogenic complexes of the Upper Ural and Magnitogorsk regions]. Ufa, IG UFSC of RAS Publ., $1998.156 \mathrm{p}$.

14. Mizens G.A., Svyazhina I.A. On the Urals Devonian paleogeography. Lithosphere, 2007, no. 2, pp. 29-44. In Rus.

15. Seravkin I.B., Kosarev A.M., Salikhov D.N., Znamensky S.E., Rodichesva Z.I., Rykus M.V., Snachev V.I. Vulkanizm Yuzhnogo Urala [Volcanism of the Southern Urals]. Moscow, Nauka Publ., 1992. $197 \mathrm{p}$.

16. Yazeva R.G., Bochkarev V.V. Geologiya i geodinamika Yuzhnogo Urala (Opyt geodinamicheskogo kartirovaniya) [Geology and geodynamics of the Southern Urals (Experience of geodynamic mapping)]. Ekaterinburg, IGG UB RAS Publ., 1998. 203 p.

17. Kosarev A.M., Puchkov V.N., Seravkin I.B. Petrol-geochemical features of Middle Devonian-Early Carboniferous island-arc and collision volcanics of the Magnitogorsk zone in the geodynamic context. Lithosphere, 2006, no. 1, pp. 3-21. In Rus.

18. Verma S.P., Armstrong-Altrin J.S. New multi-dimensional diagrams for tectonic discrimination of siliciclastic sediments and their application to Precambrian basins. Chemical Geology, 2013, no. 355 , pp. 117-133.

19. Petrograficheskiy kodeks. Magmaticheskie, metamorficheskie, metasomaticheskie, impaktnyye obrazovaniya [Petrographic $\mathrm{Co}_{-}$ de. Magmatic, metamorphic, metasomatic, impact formations]. Eds. O.A. Bogatikov, 0.V. Petrov. St. Petersburg, VSEGEI Publ., 2008. $200 \mathrm{p}$.

20. Maynard J.B., Valloni R., Ho Shing Ju. 1982. Composition of modern deep-sea sands from arc-related basin. Geological Society London Special Publications, vol. 10, no. 1, pp. 551-561.

21. Roser B.P., Korsch R.J. Determination of tectonic settings of sandstone-mudstone suits using $\mathrm{SiO}_{2}$ content and $\mathrm{K}_{2} \mathrm{O} / \mathrm{Na}_{2} \mathrm{O}$ ratio. Journal of Geology, 1986, vol. 94, no. 5, pp. 635-650.

22. Bhatia M.R. Plate tectonic and geochemical composition of sandstones. Journal of Geology, 1983, no. 91, pp. 611-627.

23. Shvanov V.N. Peschanye porody i metody ikh izucheniya [Sand rocks and methods for their study]. Leningrad, Nedra Publ., 1969. $248 \mathrm{p}$.

24. Maslov A.V., Gareev E.Z., Isherskaya M.V. «Standard» discriminant paleogeodynamic diagrams and platform sandstone associations. Otechestvennaya geologiya, 2012, no. 3, pp. 55-65. In Rus.

25. Ryan K.M., Williams D.M. Testing the reliability of discrimination diagrams for determining the tectonic depositional environment of ancient sedimentary basins. Chemical Geology, 2007, no. 242 , pp. 103-125.

26. Armstrong-Altrin J.S., Verma S.P. Critical evaluation of six tectonic setting discrimination diagrams using geochemical data of Neogene sediments from known tectonic settings. Sedimentary Geology, 2005, no. 177, pp. 115-129.

27. Zaid S.M. Petrography and geochemistry of the Middle Miocene Gebel El Rusas sandstones, Eastern Desert, Egypt: Implications for provenance and tectonic setting. Journal of Earth System Science, 2017, 126:103.

28. Verma S.P., Armstrong-Altrin J.S. Geochemical discrimination of siliciclastic sediments from active and passive margin settings. Sedimentary Geology, 2016, no. 332, pp. 1-12.

Received: 18 October 2018.

\section{Information about the authors}

Alexandr M. Fazliakhmetov, Cand. Sc, senior researcher, Institute of Geology - Subdivision of the Ufa Federal Research Centre of the Russian Academy of Sciences. 